\title{
Total Hip Replacement: Tensile Stress in Bone Cement is influenced by Cement Mantle Thickness, Acetabular Size, Bone Quality, and Body Mass Index
}

\author{
Lamvohee $\mathrm{JMS}^{1,4}$, Ingle $\mathrm{P}^{1}$, Cheah $\mathrm{K}^{2}$, Dowell $\mathrm{J}^{2,3}$ and Mootanah $\mathbf{R}^{1}$ \\ ${ }^{1}$ Medical Engineering Research Group, Faculty of Science \& Technology, Anglia Ruskin University, Chelmsford, Essex, CM1 1SQ, UK \\ ${ }^{2}$ Springfield Ramsay Hospital, Lawn Lane, Springfield, Chelmsford, Essex, CM1 7GU, UK \\ ${ }^{3}$ Mid-Essex Hospitals Trust, Broomfield Hospital, Chelmsford, Essex, CM1 7ET, UK \\ ${ }^{4}$ Reckitt Benckiser, Hull, UK
}

\begin{abstract}
Background: High stress developed in the cement mantle of a total hip replacement is reported to contribute to premature failure of acetabular components. We postulate that stress level is influenced by cement mantle thickness, acetabular size, bone quality and body mass index.

Methods: Finite element models of reconstructed hemi pelves of different sizes and acetabular diameters (46 52 and $58 \mathrm{~mm}$ ) were created from CT-Scan data. We investigated the effects of cement mantle thickness $(1,2,3$ and $4 \mathrm{~mm}$ ), acetabular size, body mass index $\left(B M I=20,25\right.$ and $\left.30 \mathrm{~kg} / \mathrm{m}^{2}\right)$ and bone quality on stress level developed in the cement mantle.

Findings: Peak tensile stresses in the cement mantle increased with a decrease in cement mantle thickness, acetabular size and bone quality and an increase in BMI.

Interpretation: Our results indicate that a 4-mm-thick cement mantle is required in small reconstructed acetabulae of $\leq 50$ - $\mathrm{mm}$ diameters, while a 1-mm thick cement mantle can be used on larger reconstructed acetabulae of $\geq 58$ $\mathrm{mm}$ diameter. Patients with poor bone quality require at least a 4-mm-thick cement mantle to reduce the risk failure caused by high stress level in the cement mantle.
\end{abstract}

Keywords: Total hip replacement; Cement mantle thickness; Acetabulum; Body mass index; Finite element method; Stress

\section{Introduction}

Cemented hip replacement, as a means to help people suffering from hip disorders to regain mobility, is used in one third of the 76,448 primary total hip replacements (THRs) carried out in the UK in 2012 [1]. Cemented THRs were used in $91 \%$ of patients who were 60 years and over and $77 \%$ of all primary THR in the UK in 2012 was conducted on this age group [1]. Despite the reduction in the use of cemented hip implants, Mäkelä et al. reported that the survival of cemented THR implants was higher than that of uncemented implants in patients aged 65 years or older [2]. The same can be deduced from the 2013 UK National Joint Register if the metal-on-metal implants are excluded from the statistics [1].

The rate of revision due to aseptic loosening could be as high as $75.4 \% 20$ years postoperatively [3]; In addition to bone resorption [4-8], poor cementing techniques can lead to premature failure of the acetabular components caused by improper mechanical interlock between the cement and the bone, as can be detected by radiolucencies [9-11].

We postulate that, if the stress level in the cement mantle is too high, the mechanical interlock between the bone and cement can be disrupted and contribute to the loosening process. McCormack et al. have shown that loosening of femoral cemented implants can be caused by a gradual process of damage accumulation in the form of initiation and propagation of numerous micro cracks in the cement which, in turn, is related to the level of stress in the cement mantles [12]. The damage accumulation process in acrylic bone cement is nonlinear and the degree of nonlinearity increases with stress [13].
During normal physiological activities, bone cement used in a THR can be subjected to high stress, which can lead to failure, given the low tensile strength of bone cement. Cement pegs, created during a THR to provide implant stability and to improve the torsional strength of the reconstructed acetabulum, can be subjected to high stress levels, especially near the neck [14,15], and where failure often occurs in vivo. We postulate that implant fixation can be improved if the cement mantle is subjected to a smooth stress distribution as opposed to high peak stress [14].

Coultrup et al.'s computational study showed that a 2 -mm-thick cement mantle would have a reduced fatigue life as compared to a 4-mm-thick cement mantle [16]. Their research also showed that a thin cement mantle might lead to mechanical overload of the cement-bone interface, thus suggesting that mechanical factors can contribute to the failure of cemented acetabular components. Zant et al. investigated the fatigue failure in the cement mantle, using a simplified acetabular replacement model [17]. They reported that high tangential and radial

*Corresponding author: Rajshree Mootanah, PhD MBA, Director, Medical Engineering Research Group and Senior Lecturer, Department of Engineering and Built Environment, Faculty of Science \& Technology Anglia Ruskin University Bishop Hall Lane Chelmsford, Essex CM1 1SQ, UK, Tel: (44) 1245 683909; Fax (44) 1245 684536; E-mail: rajshree.mootanah@anglia.ac.uk

Received March 04, 2014; Accepted March 12, 2014; Published March 14, 2014

Citation: Lamvohee JMS, Ingle P, Cheah K, Dowell J, Mootanah R (2014) Total Hip Replacement: Tensile Stress in Bone Cement is influenced by Cement Mantle Thickness, Acetabular Size, Bone Quality, and Body Mass Index. J Comput Sci Syst Biol 7: 072-078. doi:10.4172/jcsb.1000140

Copyright: (C) 2014 Lamvohee JMS, et al. This is an open-access article distributed under the terms of the Creative Commons Attribution License, which permits unrestricted use, distribution, and reproduction in any medium, provided the original author and source are credited. 

by Cement Mantle Thickness, Acetabular Size, Bone Quality, and Body Mass Index. J Comput Sci Syst Biol 7: 072-078. doi:10.4172/ jcsb. 1000140

stress lead to crack propagation in the cement mantle with the same characteristics of fatigue damage. They also concluded that cracks in the cement mantle may be completely suppressed if the stress level is well below the fatigue limit of the cement, suggesting that a lower stress could then lead to a more stable acetabular fixation.

Kumar et al. reported that the cement mantle thickness of the femoral component influences stress distribution [18]. Carter et al. [19] showed that an increase in the cement mantle thickness from 1 to 3 and $5 \mathrm{~mm}$ caused a reduction in the von Mises stresses in the cement and surrounding the cancellous bone. However several investigators have associated thick cement mantles with bone necrosis [3,20,21].

Previous computational and in vitro studies show that stress distributions and torsional strengths of the reconstructed hip joint are influenced by the geometry and configurations of the cement pegs [14,22-24]. However, our survey of current practice among orthopaedic surgeons (454 respondents) shows wide variations in surgical fixation techniques [25]. We postulate that bone quality, acetabular size and BMI also influence stress levels in the cement mantle. To our knowledge, no study has looked specifically at whether the stress developed in the cement mantle of a reconstructed hip joint is affected by a combination of these factors. This could prove clinically useful in helping surgeons optimise the preoperative plan for individual patients. Therefore, the aim of this study is to investigate the effects of cement mantle thickness, acetabular size, bone quality and body mass index on the stress distribution in the cement mantles of reconstructed hip, using finite element (FE) method.

\section{Methods}

\section{Geometry}

A hemipelvis dataset, consisting of 200 axial CT-Scan images at 1 mm intervals, was obtained from the Visible Human data set [26]. These images were imported to the commercially-available Mimics software v8.1 (Materialise, Leuven, Belgium), which acted as an interface between medical imaging and finite element (FE) packages. Separate $3 \mathrm{D}$ volumes of the cortical and cancellous bones were generated, using thresholding and region growing tools in Mimics, using the grey and Hounsfield values of the CT scan images (ranging from - 37 to 1027 HU). These were exported to I-Deas v11.0 (UGS PLM Softwares, Texas, USA) FE pre- and post-processing package to construct a 3D hemipelvis model. This model was then scaled up and down to generate one larger and one smaller virtual hemipelvis. The three models were then virtually reconstructed to produce reamed acetabulae of diameters 46, 52 (unscaled model) and $58 \mathrm{~mm} \mathrm{[26].}$

Virtual surgical fixation of the acetabular component (ultra high molecular weight polyethylene smooth cup) was simulated, including reaming and drilling of anchorage holes. The acetabulum was virtually reamed into a hemispherical bed, which is reported to result in a uniform cement mantle, smooth stress distribution and, consequently, a stable reconstruction $[27,28]$. Three $8-\mathrm{mm}$ deep and 8 - $\mathrm{mm}$ diameter anchorage holes were then modelled perpendicular to the bed of the acetabulum, one in each of the iliac, pubic and ischial regions, to simulate a good cemented surgical fixation [15].

\section{Element sizes}

The three reconstructed hemipelves, each consisting of the three hip bones, cement mantle, acetabular component and femoral implant, were meshed, using 10-noded tetrahedral elements. Each volume of the reconstructed hemipelvis was meshed with different element sizes to conduct a sensitivity analysis on element size. Element sizes were reduced until peak stress results converged and the level of mesh refinement no longer affected local stress values by more than $5 \%$. The selected element sizes were $1 \mathrm{~mm}$ for the cortical bone, $2 \mathrm{~mm}$ for the cancellous bone, $1 \mathrm{~mm}$ for the subchondral bone, $1 \mathrm{~mm}$ for the cement mantle and pegs, $3 \mathrm{~mm}$ for the acetabular component and $3 \mathrm{~mm}$ for the 22-mm Charnley Roundback femoral prosthesis.

The ISB coordinate system (Figure 1) was used to position the acetabular component in an abduction angle of $45^{\circ}$ and anterversion angle of $15^{\circ}$ to simulate surgical practice [29]. We simulated an increase in the cement mantle thickness by reducing the thickness of the acetabular component, as would be the case during surgery. The femoral prosthesis was included in the model to ensure a realistic introduction of the hip joint reaction force to the reconstructed acetabulae. To save on computational time, only the head of the femoral implant was simulated. A $22-\mathrm{mm}$ diameter femoral head was used in all the models. The element sizes of the different volumes at each interface were kept the same to reduce element distortion.

\section{Material properties}

For this comparative study, isotropic and homogeneous properties were assumed for all the hip bones, given that the acetabulum is not highly anisotropic [30]. Two sets of investigations in relation to bone quality were carried out, one simulating patients with normal bone quality and the other simulating patients with poor bone quality by reducing the bone elastic modulus. The Young's Modulus and Poisson's ratio, respectively, for the reconstructed hemi pelves were taken as; cortical bone: $17 \mathrm{GPa}, 0.3$; subcondral bone: $1.15 \mathrm{GPa}, 0.3$; cancellous bone: $0.05 \mathrm{GPa}, 0.2$; cement mantle and pegs: $2 \mathrm{GPa}, 0.3$; acetabular component: $0.7 \mathrm{GPa}, 0.3$; and femoral implant: $200 \mathrm{GPa}$, 0.28 [30-33]. To simulate bones of reduced quality, the elastic modulus of the cancellous bone was reduced to $10 \%$ of the original and that of the cortical bone and subchondral bone to $50 \%$ [34].

\section{Boundary conditions}

The compressive force was applied to the femoral head at an angle of $16^{\circ}$ to the vertical y-axis $[35,36]$, as defined in the ISB recommendations for the hip joint coordinate system [29] (Figure 1). A novel approach, whereby the body mass index (BMI) and hemi pelvic acetabular sizes were used to compute the corresponding compressive forces, was implemented. To our knowledge, there is no data available that relates the hip joint compressive forces to acetabular size. We therefore used published data on the correlation between the acetabular size and the person's height, based on 18 hemi pelves [37] and the body mass index (BMI) equation to calculate the person's mass for each specific BMIs. The BMI equation is given by:

$$
B M I=m / h^{2}
$$

Where $\mathrm{h}$ is height in meters and $\mathrm{m}$ is body mass in $\mathrm{kg}$.

The compressive force acting on each acetabulum was calculated as three times the body weight, the peak hip force calculated at $20 \%$ of the stance phase when walking at $4 \mathrm{~km} / \mathrm{hr}$ [38] (Table 1). The forces were calculated to simulate patients with BMI of 30 . This is because THR patients usually have BMIs of $25 \mathrm{~kg} / \mathrm{m}^{2}$ and over [39]. BMI values were then altered to investigate their effects on the cement mantle stress.

The nodes situated in the sacro-iliac areas and the pubic support areas were fixed in all six degrees of freedom to simulate sacral and 
Citation: Lamvohee JMS, Ingle P, Cheah K, Dowell J, Mootanah R (2014) Total Hip Replacement: Tensile Stress in Bone Cement is influenced by Cement Mantle Thickness, Acetabular Size, Bone Quality, and Body Mass Index. J Comput Sci Syst Biol 7: 072-078. doi:10.4172/ jcsb.1000140
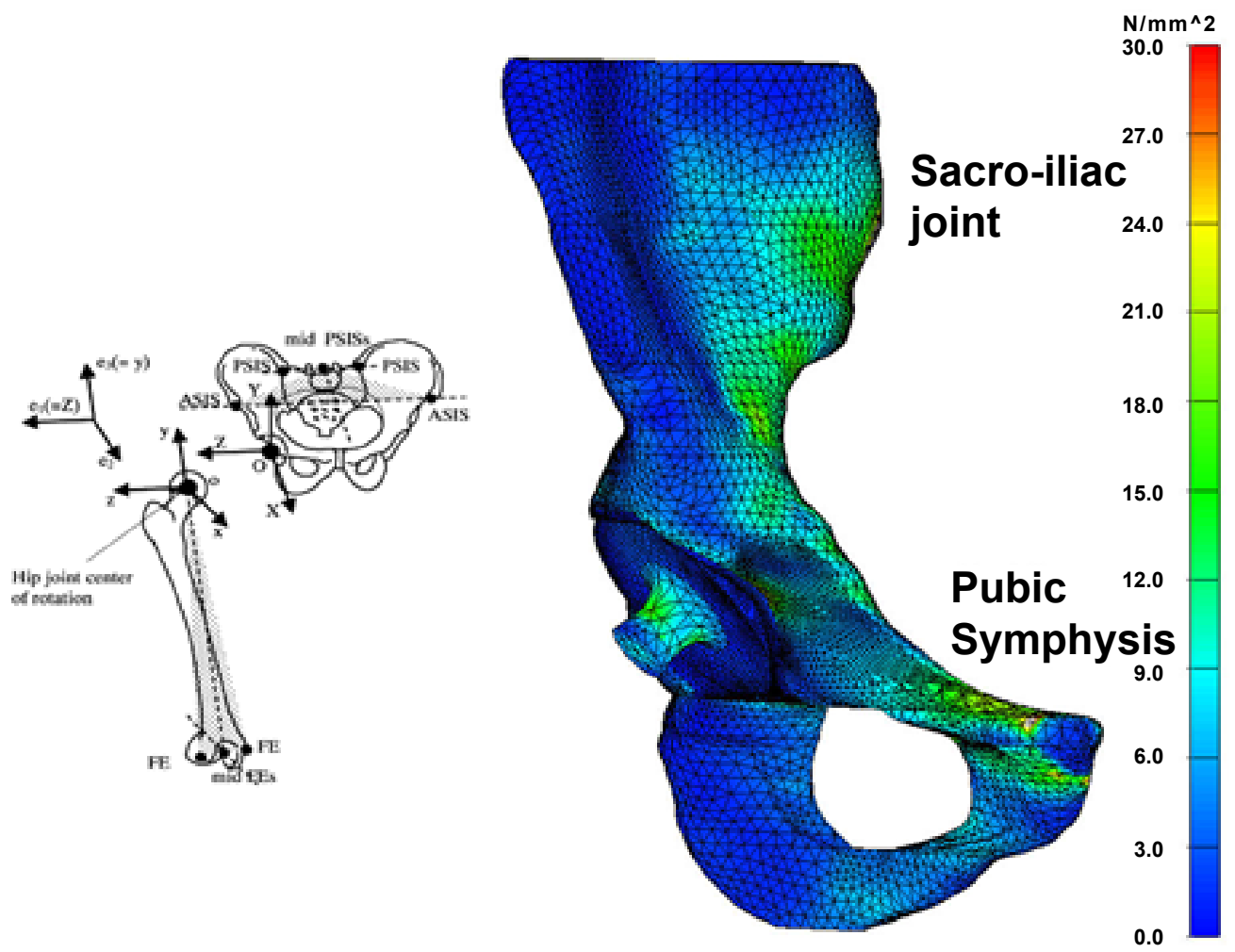

Figure 1: Left) Pelvic coordinate system used to position the direction of force acting on a reconstructed hip joint - Illustration of the pelvic coordinate system (XYZ), femoral coordinate system (xyz), and the joint coordinate system for the right hip joint (Source: ISB recommendation, 2002). Right) Von Mises stress distribution in the cement mantle of a reconstructed total hip replacement with a 46-mm-diameter acetabulum.

\begin{tabular}{|c|c|c|c|c|}
\hline Acetabular size (mm) & Height of patient, $h(m)$ & BMI of patient $\left(\mathrm{kg} / \mathrm{m}^{2}\right)$ & Mass of patient $m=h^{2} \times B M I(\mathbf{k g})$ & Compressive force $F=3 m g(\mathrm{~N})$ \\
\hline \multirow[t]{3}{*}{46} & 1.460 & 20 & 42.63 & 1255 \\
\hline & & 25 & 53.29 & 1568 \\
\hline & & 30 & 63.95 & 1882 \\
\hline \multirow[t]{3}{*}{52} & 1.642 & 20 & 53.92 & 1587 \\
\hline & & 25 & 67.40 & 1984 \\
\hline & & 30 & 80.88 & 2380 \\
\hline \multirow[t]{3}{*}{58} & 1.825 & 20 & 66.61 & 1960 \\
\hline & & 25 & 83.27 & 2451 \\
\hline & & 30 & 99.92 & 2941 \\
\hline
\end{tabular}

Table 1: Compressive force acting in the hip joint, calculated from body mass index (BMI). Subjects' heights for each acetabular size were obtained from the work of Thompson ac co-investigators (2000).

pubic support of the pelvic bone [30]. Contact elements were used at the subchondral bone and cement mantle interface to represent the mechanical interlock between the bone and the cement [40]. A diametral clearance of $0.1 \mathrm{~mm}[41,42]$ was modelled and frictionless contact elements [30] were used at the interface between the femoral head implant and the acetabular component. Our sensitivity analyses of the effect of frictional moments on the stress distribution in the reconstructed hemi-pelves showed only a small relative change of 2-3\% in the tensile stress level in the cement mantle. Hence, it was reasonable to assume frictionless contact between the acetabular component and the femoral head implant. The nodes at the interface of the subchondral bone and cancellous bone were merged to represent perfect bonding. The same process was applied to the cortical and cancellous bone interface.
Since cancellous bone consists of honeycomb structure which allows good cement interdigitation during cement pressurization, the bonding between the cancellous bone and bone cement was represented by merging the nodes at the bone-cement interface. The nodes on the outer surface of the acetabular cup were merged with those of the inner surface of the cement mantle since this interface rarely debonds.

Finite element analyses were conducted on the simulated reconstructed hip models with acetabular diameters of 46,52 and $58 \mathrm{~mm}$ to predict stress distribution in the cement mantle, using I-DEAS 11.0 pre- and post-processing modules. The parameters that were investigated for each model were 1) thickness of cement mantle, ranging from 1 to $4 \mathrm{~mm}$, in increment of $1 \mathrm{~mm}, 2$ ) BMIs of 20, 25 and 30 $\mathrm{kg} / \mathrm{m}^{2}$ and 3 ) normal and poor bone quality (with $10 \%$ reduced elastic modulus for the cancellous bone and 50\% reduced elastic modulus 
Citation: Lamvohee JMS, Ingle P, Cheah K, Dowell J, Mootanah R (2014) Total Hip Replacement: Tensile Stress in Bone Cement is influenced by Cement Mantle Thickness, Acetabular Size, Bone Quality, and Body Mass Index. J Comput Sci Syst Biol 7: 072-078. doi:10.4172/ jcsb. 1000140

for the cortical and subchondral bones [34]). These parameters were investigated in order to cover a wide spectrum of candidates for cemented THR.

Following the FE analyses, stress distributions and peak tensile and shear stress in all the models were perdicted, in particular, at the neck of the anchorage holes, where failure normally occurs. Tensile stress as then compared to a threshold value of $8.25 \mathrm{MPa}$ that represents a $95 \%$ probability of survivorship of the cement mantle over 10 million cycles. This threshold value was calculated from the following equation, developed by Murphy and Prendergast [13].

$$
P_{S}=0.003 \sigma^{3}-0.1154 \sigma^{2}+1.3427 \sigma-3.9564
$$

where $P_{s}$ is the probability of survivorship and $\sigma$ is the stress developed in the cement mantle

In addition, the volume of cement subjected to different stress levels were grouped into different categories. The elements within a specific stress range category were first identified and then the volume occupied by these elements was calculated. The number of cycles to cement mantle failure for different stress levels were predicted and compiled. The number of cycles to failure, derived by Murphy and Prendergrast [13] is given by:

$$
\sigma=-0.4395 \log _{10}\left(N_{f}\right)+40.42
$$

where $\sigma$ is the stress developed in the cement and $\mathrm{N}_{\mathrm{f}}$ is the number of cycles to failure.

Results for tensile stress developed in each FE model simulating BMIs of 20,25 and $30 \mathrm{~kg} / \mathrm{m}^{2}$ with different sizes of acetabulae were also compiled and plotted against BMI. For each acetabular size and cement mantle thickness, equations were derived to correlate BMI and tensile stress in the cement mantle (Table 3 ).

\section{Results and Analyses}

Effect of acetabular size and cement mantle thickness on stress distribution in the reconstructed acetabula and number of cycles to failure

When the hemi pelvis was loaded statically, the initial stress transfer occurred in the superior quadrant of the acetabulum. This pattern was observed in each reconstructed hemi pelvis. FE model with different acetabular size and cement mantle thickness. The stress was then transferred through the bone to the sacro-iliac joint, as shown in Figure 1 . Von Mises stress in the cortical bone were approximately 50 times higher than the stress developed in the cancellous bone.

Peak von Mises and shear stress developed in the acetabular components decreased with an increase in cement mantle thickness. For example, for the 46-mm acetabulum, as cement mantle thickness increased from 1 to $4 \mathrm{~mm}$, peak von Mises stress in the acetabular cup decreased from 8.24 to $7.78 \mathrm{MPa}$. This trend was observed for all acetabulae of different sizes. However, an increase in acetabular size increased von Misses stress in the acetabular and femoral icomponents. For example, for a 1-mm-thick cement mantle, as acetabular diameter increased from 46 to 52 and $56 \mathrm{~mm}$, peak von Mises stress in the cup increased from 8.24 to 9.35 and $10.9 \mathrm{MPa}$, respectively. The same trend was observed for shear stress.

An increase in cement mantle thickness decreased the peak tensile (maximum principal) stress in the cement mantle. For the $46-\mathrm{mm}$ diameter acetabulum and a BMI of $30 \mathrm{kN} / \mathrm{m}^{2}$, an increase in cement mantle thickness from 1 to $4 \mathrm{~mm}$ reduced the cement mantle peak tensile stress from 10.32 to $8.14 \mathrm{MPa}$ (Figure 3). The same trend was observed for shear stress. Maximum shear stress decreased with an increase in the cement mantle thickness. Peak shear stress as high as $5.36 \mathrm{MPa}$ was recorded in the 46-mm FE model and $1-\mathrm{mm}$ cement mantle thickness $\left(\mathrm{BMI}=30 \mathrm{~kg} / \mathrm{m}^{2}\right)$, while peak shear stress of $3.67 \mathrm{MPa}$ was recorded for the same size of acetabulum and the same BMI, but with a 4-mm thick cement mantle.

Table 2 displays the peak tensile and shear stress and number of cycles to failure for different acetabular sizes and cement mantle thickness when BMI is $30 \mathrm{~kg} / \mathrm{m}^{2}$. The values in bold and in italic represent tensile stress above the threshold value of $8.25 \mathrm{MPa}$ [13]. An increase in cement mantle thickness increased the number of cycles to cement mantle failure increased. The same trend was observed for the different acetabular sizes. The volumetric cumulative frequency distribution graphs indicate that stress distribution in the cement mantle is improved with an increase mantle thickness. Larger volumes of cement mantle with lower stress levels were observed in thicker mantles. A typical representation for a 46- $\mathrm{mm}$ acetabular size is shown in Figure 2. The cumulative frequency distribution curves showed that the reconstructed FE hemi pelvic model with 4-mm thick cement mantle is more skewed to the left hand side portion of the graph, which corresponds to lower stress levels.

\section{Effect of body mass index on cement mantle stress}

An increase in BMI increased tensile stress level in the cement

\begin{tabular}{|c|c|c|c|c|c|c|c|c|}
\hline $\mathrm{BMI}=\mathbf{3 0}$ & & & STR & ES IN CE & IT MANTL & PA) & & \\
\hline Thickness & $1 \mathrm{~mm}$ & ent & $2 \mathrm{~mm}$ & ent & $3 \mathrm{~mm}$ & ent & $4 \mathrm{mn}$ & ent \\
\hline Acetabular size (mm) & Tensile & Shear & Tensile & Shear & Tensile & Shear & Tensile & Shear \\
\hline 46 & 10.32 & 5.36 & 10.18 & 4.84 & 8.99 & 3.82 & 8.14 & 3.67 \\
\hline Number of cycles to failure $\left(\times 10^{6}\right)$ & 7.04 & & 7.6 & & 14.1 & & 22.1 & \\
\hline 52 & 9.71 & 4.95 & 8.20 & 4.55 & 7.65 & 3.73 & 7.26 & 3.56 \\
\hline Number of cycles to failure $\left(\times 10^{6}\right)$ & 9.72 & & 21.4 & & 28.6 & & 35.1 & \\
\hline 58 & 8.03 & 4.5 & 7.27 & 3.61 & 6.81 & 3.37 & 6.73 & 3.21 \\
\hline Number of cycles to failure $\left(\times 10^{6}\right)$ & 23.4 & & 34.9 & & 44.4 & & 46.3 & \\
\hline
\end{tabular}
mantle, as expected. The same observation was made for different

Table 2: Tensile stress, shear stress and number of cycles $\left(\times 10^{6}\right)$ to failure in simulated reconstructed hip joints with different acetabular sizes.

\begin{tabular}{|l|c|c|c|c|}
\hline Acetabular size $\mathbf{( m m})$ & 1-mm cement & 2-mm cement & 3-mm cement \\
\hline $\mathbf{4 6}$ & $\sigma=0.272 x+2.0733\left(R^{2}=0.988\right)$ & $\sigma=0.298 x+1.1711\left(R^{2}=0.9936\right)$ & $\sigma=0.279 x+0.6217\left(R^{2}=1\right)$ & $\sigma=0.244 x+0.7744\left(R^{2}=0.9958\right.$ \\
\hline $\mathbf{5 2}$ & $\sigma=0.271 x+1.5283\left(R^{2}=0.9957\right)$ & $\sigma=0.24 x+0.9933\left(R^{2}=0.9999\right)$ & $\sigma=0.242 x+0.41\left(R^{2}=0.9992\right)$ & $\sigma=0.228 x+0.46\left(R^{2}=0.9963\right)$ \\
\hline $\mathbf{5 8}$ & $\sigma=0.233 x+1.0183\left(R^{2}=0.999\right)$ & $\sigma=0.236 x+0.2933\left(R^{2}=0.9775\right)$ & $\sigma=0.234 x+0.15\left(R^{2}=0.9946\right)$ & $\sigma=0.21 x+0.44\left(R^{2}=0.9997\right)$ \\
\hline
\end{tabular}

Table 3: Equations correlating cement mantle tensile stress $(\sigma, \mathrm{MPa})$ and $\mathrm{BMI}\left(\mathrm{x}, \mathrm{kg} / \mathrm{m}^{2}\right)$. 
Citation: Lamvohee JMS, Ingle P, Cheah K, Dowell J, Mootanah R (2014) Total Hip Replacement: Tensile Stress in Bone Cement is influenced by Cement Mantle Thickness, Acetabular Size, Bone Quality, and Body Mass Index. J Comput Sci Syst Biol 7: 072-078. doi:10.4172/ jcsb.1000140

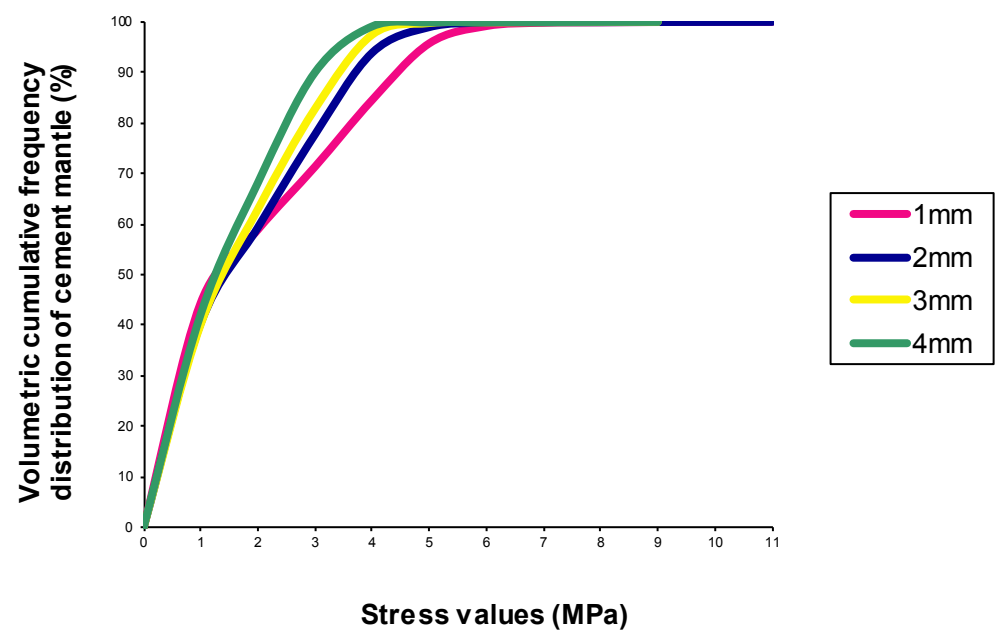

Figure 2: A typical set of volumetric cumulative frequency distributions of bone cement at different tensile stress levels for different cement mantle thicknesses acetabular size $=46 \mathrm{~mm}$, body mass index $=30 \mathrm{~kg} / \mathrm{m}^{2}$.

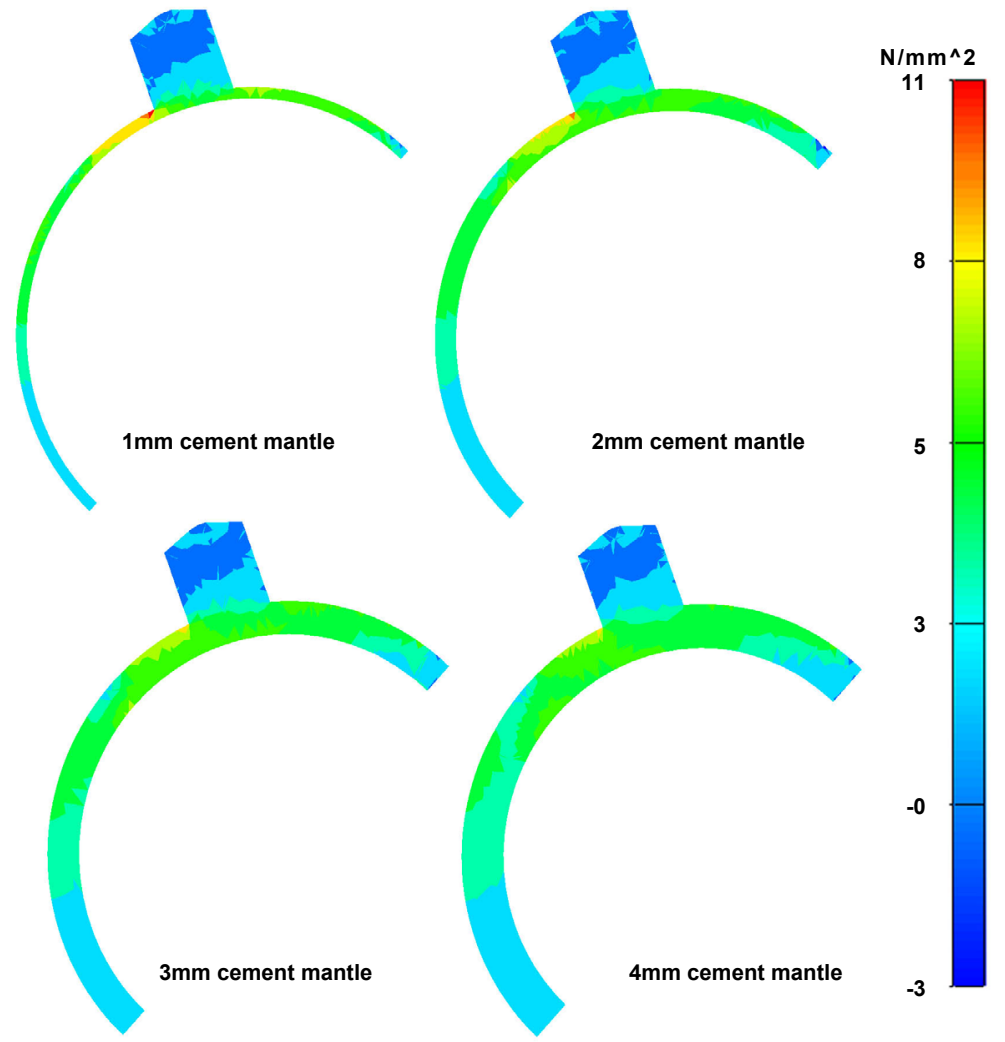

Figure 3: A typical pattern of tensile stress distribution in the cement mantle of a reconstructed total hip replacement with a 46-mm-diameter acetabulum and a body mass index of $30 \mathrm{~kg} / \mathrm{m}^{2}$. Section passes through the anchorage hole modelled in the iliac bone.

acetabular sizes. The equations generated showed that there is a linear correlation between tensile stress developed in the cement mantle and the corresponding BMI (Table 3).

\section{Effect of bone material properties on cement mantle stress}

Poor bone quality, simulated by reduced elastic moduli, resulted in an increase in tensile and shear stress in the hemi pelvis and an increase in tensile stress in the cement mantle by $45 \%$.

\section{Discussion}

The main objective of this study was to investigate, by FE method, the effect of cement mantle thickness, acetabular size, bone quality and BMI on stress developed in cement mantles of simulated reconstructed hips. Results of FE analyses showed that these factors influence the peak tensile stress values in the cement mantle. Reconstructed hemi pelvic models with large acetabular size have lower peak stress developed in 
Citation: Lamvohee JMS, Ingle P, Cheah K, Dowell J, Mootanah R (2014) Total Hip Replacement: Tensile Stress in Bone Cement is influenced by Cement Mantle Thickness, Acetabular Size, Bone Quality, and Body Mass Index. J Comput Sci Syst Biol 7: 072-078. doi:10.4172/ jcsb. 1000140

the cement mantle compared to those with smaller sizes. This is because thicker acetabular components are implanted in larger acetabulae, which helps distribute the higher compressive loads. The trend of the results indicates that thicker cement mantle could help reduce the level of stress generated and improve the probability of survivorship of the cement fixation. However, thick cement mantle thickness presents the risk of bone necrosis $[12,21,22]$.

Our findings agree with the works of Lankester et al. [28], Herberts and Malchau, and Carter et al. [3,19]. Lankester et al. [28] investigated the optimum thickness for the acetabular cement mantle, using a biomechanical analysis. Their study suggests that surgeons should aim to achieve a mantle at least $2 \mathrm{~mm}$ thick, which agrees with our findings for acetabular diameter larger than $52 \mathrm{~mm}$. However, our study showed that, for acetabular diameters of $50 \mathrm{~mm}$ or less, a cement mantle thickness of at least $4 \mathrm{~mm}$ is required for long-term stable fixation of the acetabular component. This is not in line with the study of Lankester et al. [28] who recommended the use of a $2 \mathrm{~mm}$ thick cement mantle for acetabular cup sizes ranging from $44 \mathrm{~mm}$ to $52 \mathrm{~mm}$. Our findings differ from theirs, possibly because they used mahogany blocks to simulate the acetabulum, whereas we modelled the whole reconstructed hemi pelvis in a more physiological manner to investigate the stress behaviour during the transfer process from the cement mantle to the pelvic bone. Unlike our model, the mahogany block did not behave as the physiological sandwich construction of the cancellous, subchondral and cortical bones.

Our study also shows that the patient's bone quality, acetabular size and BMI should be taken into consideration when surgically reconstructing the acetabulum. An increase in the patient's BMI generated an increase in the stress level developed in the cement mantle, as deduced from the derived equations correlating BMI to tensile stress in Table 3. These equations could be used by orthopaedic surgeons to predict tensile stress in the cement mantle for a particular patient with a specific BMI, acetabular size and BMI. If the calculated tensile stress is above the threshold value of $8.25 \mathrm{MPa}$ [13], then the surgeon could consider increasing the cement mantle thickness or choose a different fixation method.

We acknowledge that the FE models could better represent physiological conditions by including heterogenous bone properties, muscle forces, simulating cyclic loading and using multiple CT scan data set to create the hemi pelves with different acetabular sizes. We have therefore verified our FE model by conducting a parallel in vitro study on the Third Generation synthetic Sawbones (Sawbones Europe AB, Malmö, Sweden) [15]. The aim of that study was to investigate the effect of cement mantle thickness on the stability of cemented reconstructed acetabulum. The overall results showed that, for a reconstructed 56-mm-diameter acetabulum, there is less micromotion at the bone-cement interface with a $2-\mathrm{mm}$ thick cement mantle, compared to an interface with a 1-mm thick cement mantle (Lamvohee, 2007) [43]. These results also show that thicker cement mantles reduce the micromotion, which could lead to a better probability of survivorship. Our FE results showed that thicker cement mantles result in lower stress levels and higher number of cycles to failure.

\section{Conclusion}

Results of this study show that different methods of fixation should be used for patients with different acetabular size, bone quality and BMI. The correct cement mantle thickness should be used $r$ to keep the stress level below the threshold value of $8.25 \mathrm{MPa}$. Our results suggest that for a large (diameter $>58 \mathrm{~mm})$, medium $(50-58 \mathrm{~mm})$ and small $(<50 \mathrm{~mm})$ acetabulum, the minimum cement mantle thickness should be 1, 2 and $4 \mathrm{~mm}$, respectively. The equations correlating tensile stress in cement mantles to body mass index for different acetabular size and cement mantle thickness can be used by orthopaedic surgeons as a predictive tool to select the appropriate cement mantle thickness for different THR patients. This study also suggest that a cement mantle thickness of $4 \mathrm{~mm}$ could help reduce cement mantle stress in patients with poor bone quality. This ability to make informed decision on implant fixation techniques could prove clinically useful in helping surgeons optimize the preoperative plan for individual patients.

\section{Acknowledgement}

The authors would like to acknowledge the International Society of Biomechanics, for providing a matching dissertation grant, Materialise, for the Mimics Innovation Award, Dr Rob Walker for his advice, and Anglia Ruskin University for funding this research.

\section{References}

1. NJR Editorial Board. National Joint Registry for England Wales and Northern Ireland - Surgical data to Becember 2012

2. Mäkelä KT, Matilainen M, Pulkkinen P, Fenstad AM, Havelin L, et al. (2014) Failure rate of cemented and uncemented total hip replacements: register study of combined Nordic database of four nations. BMJ 348: 77592

3. Herberts $\mathrm{P}$, Malchau $\mathrm{H}$ (2000) Long-term registration has improved the quality of hip replacement: a review of the Swedish THR Register comparing 160,000 cases. Acta Orthop Scand 71: 111-121.

4. Callaghan JJ, Templeton JE, Liu SS, Pedersen DR, Goetz DD, et al. (2004) Results of Charnley total hip arthroplasty at a minimum of thirty years. A concise follow-up of a previous report. J Bone Joint Surg Am 86-86A: 690-5.

5. Jones LC, Frondoza C, Hungerford DS (1999) Immunohistochemical evaluation of interface membranes from failed cemented and uncemented acetabular components. J Biomed Mater Res 48: 889-898.

6. Schmalzried TP, Kwong LM, Jasty M, Sedlacek RC, Haire TC, et al. (1992) The mechanism of loosening of cemented acetabular components in total hip arthroplasty. Analysis of specimens retrieved at autopsy. Clin Orthop Relat Res :60-78.

7. Zicat B, Engh CA, Gokcen E (1995) Patterns of osteolysis around total hip components inserted with and without cement. J Bone Joint Surg Am 77: 432439.

8. Wroblewski BM, Fleming PA, Siney PD (1999) Charnley low-frictional torque arthroplasty of the hip. 20-to-30 year results. J Bone Joint Surg Br 81: 427-430.

9. García-Cimbrelo E, Diez-Vazquez V, Madero R, Munuera L (1997) Progression of radiolucent lines adjacent to the acetabular component and factors influencing migration after Charnley low-friction total hip arthroplasty. J Bone Joint Surg Am 79: 1373-1380.

10. Ranawat CS, Peters LE, Umlas ME (1997) Fixation of the acetabular component. The case for cement. Clin Orthop Relat Res: 207-215.

11. Ritter MA, Zhou H, Keating CM, Keating EM, Faris PM, et al. (1999) Radiological factors influencing femoral and acetabular failure in cemented Charnley total hip arthroplasties. J Bone Joint Surg Br 81: 982-986.

12. McCormack BA, Prendergast PJ (1999) Microdamage accumulation in the cement layer of hip replacements under flexural loading. J Biomech 32: 467475.

13. Murphy $B$, Prendergast $P(2000)$ On the magnitude and variability of the fatigue strength of acrylic bone cement. Int J Fatigue 22: 855-864.

14. Mootanah R, Ingle P, Dowell J, Cheah K, Shelton JC (2000) Fixation of the acetabular cup in cemented total hip replacement: improving the anchorage hole profile using finite element method. Technol Health Care 8: 343-355

15. Mootanah R, Dowell JK, Cheah K, Ingle P, Shelton JC (2007) Configuration of anchorage holes affects fixation of the acetabular component in cemented total hip replacement--a finite element study. Comput Methods Biomech Biomed Engin 10: 439-445.

16. Coultrup OJ, Hunt C, Wroblewski BM, Taylor M (2010) Computational 
Citation: Lamvohee JMS, Ingle P, Cheah K, Dowell J, Mootanah R (2014) Total Hip Replacement: Tensile Stress in Bone Cement is influenced by Cement Mantle Thickness, Acetabular Size, Bone Quality, and Body Mass Index. J Comput Sci Syst Biol 7: 072-078. doi:10.4172/ jcsb.1000140

assessment of the effect of polyethylene wear rate, mantle thickness, and porosity on the mechanical failure of the acetabular cement mantle. J Orthop Res 28: 565-570.

17. Zant NP, Wong CK, Tong J (2007) Fatigue failure in the cement mantle of a simplified acetabular replacement model. Int J Fatigue 29: 1245-1252.

18. Kumar YS, Pant B, Darunkumar Singh K (2009) Thickness effects on maximum von-Mises stress of a cement mantle in total hip replacement - a finite element study. J Appl Biomater Biomech 7: 111-115.

19. Carter DR, Vasu R, Harris WH (1982) Stress distributions in the acetabular region--II. Effects of cement thickness and metal backing of the total hip acetabular component. J Biomech 15: 165-170.

20. Revie I, Wallace M, Orr J (1994) The effect of PMMA thickness on thermal bone necrosis around acetabular sockets. Proc Inst Mech Eng Part H J Eng Med 208: 45-51.

21. Whitehouse MR, Atwal NS, Pabbruwe M, Blom AW, Bannister GC (2014) Osteonecrosis with the use of polymethylmethacrylate cement for hip replacement: thermal-induced damage evidenced in vivo by decreased osteocyte viability. Eur Cell Mater 27: 50-62.

22. Mburu G, Aspden RM, Hutchison JD (1999) Optimizing the configuration of cement keyholes for acetabular fixation in total hip replacement using Taguch experimental design. Proc Inst Mech Eng H 213: 485-492.

23. Mootanah R, Dowell JK, Cheah K, Ingle P, Shelton JC (2008) Configuration of anchorage holes affects cemented fixation of the acetabular component in total hip replacement - An in vitro study. Technol Health Care 16: 19-30.

24. Oh I (1983) A comprehensive analysis of the factors affecting acetabular cup fixation and design in total hip replacement arthroplasty: a series of experimental and clinical studies. Hip 1983:129-177.

25. Mootanah R, Ingle P, Cheah K, Dowell JK, Shelton JC (2004) Total hip replacement: results of a postal survey of current practice on the cement fixation of the acetabular cup in the UK. Hip International 14: 155-162.

26. Peitgen $\mathrm{HO}$, Berghorn WBM, Eberhardt $\mathrm{T}$, Habermalz $\mathrm{E}$, Juergens $\mathrm{H}$, et al (1998) The Complete Visible Human: The complete high-resolustion male and female anatomical datasets from the Visible Human Project TM 1998.

27. Oh I, Sander TW, Treharne RW (1985) Total hip acetabular cup flange design and its effect on cement fixation. Clin Orthop Relat Res: 304-309.

28. Lankester B, Stoney J, Gheduzzi S, Miles A, Bannister G (2004) An in-vitro evaluation of optimal acetabular cement mantle thickness. Journal of Bone \& Joint Surgery, British Volume 86 SUPP I: 75-76.

29. Wu G, Siegler S, Allard P, Kirtley C, Leardini A, et al. (2002) ISB recommendation on definitions of joint coordinate system of various joints for the reporting of human joint motion--part I: ankle, hip, and spine. International Society of Biomechanics. J Biomech 35: 543-548.

30. Dalstra M, Huiskes R, Odgaard A, van Erning L (1993) Mechanical and textura properties of pelvic trabecular bone. J Biomech 26: 523-535.

31. Choi K, Kuhn JL, Ciarelli MJ, Goldstein SA (1990) The elastic moduli of human subchondral, trabecular, and cortical bone tissue and the size-dependency of cortical bone modulus. J Biomech 23: 1103-1113.

32. Phillips AT, Pankaj, Usmani AS, Howie CR (2004) The effect of acetabular cup size on the short-term stability of revision hip arthroplasty: a finite element investigation. Proc Inst Mech Eng H 218: 239-249.

33. Hoeltzel DA, Walt MJ, Kyle RF, Simon FD (1989) The effects of femoral head size on the deformation of ultrahigh molecular weight polyethylene acetabular cups. J Biomech 22: 1163-1173.

34. Dalstra M, Frich LH, Sneppen O (1996) The loss of load bearing capability in rheumatoid glenoids. Proceedings of the 10th European Society of Biomechanics 1-178.

35. Bergmann G, Graichen F, Rohlmann A (1993) Hip joint loading during walking and running, measured in two patients. J Biomech 26: 969-990.

36. Oka M (1993) Load-bearing mechanisms of natural and artificial joints. Hip biomechanics 1993: 255-263.

37. Thompson MS1, Dawson T, Kuiper JH, Northmore-Ball MD, Tanner KE (2000) Acetabular morphology and resurfacing design. J Biomech 33: 1645-1653.

38. Paul JP (1967) Forces transmitted by the joints in the human body. Proceedings of the Institution of Mechanical Engineers, Conference Proceedings 181: 8-15.

39. CIHI (2013) Hip and Knee Replacements in Canada: Canadian Joint Replacement Registry 2013 Annual Report.

40. Ramaniraka NA, Rakotomanana LR, Leyvraz PF (2000) The fixation of the cemented femoral component. Effects of stem stiffness, cement thickness and roughness of the cement-bone surface. J Bone Joint Surg Br 82: 297-303.

41. Kurtz S, Giddings V, Muratoglu O, O'Connor D, Harris W, et al. (2000) Stresses in highly crosslinked acetabular component for total hip replacement. In: 46th Annual Meeting, Orthopaedic Research Society, 12-15 March, Orlando.

42. Oki H, Ando M, Omori H, Okumura Y, Negoro K, et al. (2004) Relation between vertical orientation and stability of acetabular component in the dysplastic hip simulated by nonlinear three-dimensional finite element method. Artif Organs 28: 1050-1054.

43. Lamvohee JMS, Mootanah R, Dowell JK, Ingle P (2007) Patients' bone morphology and bone quality affect the performance of fixation techniques in cemented total hip replacements. Journal of Biomechanics 40 Supplement 2 : S228. 